\title{
Distribution of arachidonic acid and other fatty acids in the lipids of guinea-pig uterus and plasma in relation to uterine prostaglandin synthesis
}

\author{
H. Anne Leaver and N. L. Poyser \\ Department of Pharmacology, University of Edinburgh, 1 George Square, \\ Edinburgh EH8 9JZ, U.K.
}

\begin{abstract}
Summary. Prostaglandin precursor fatty acids, predominantly arachidonic acid, were found in the different lipid classes of guinea-pig uterus and plasma on Days 7 and 15 of the oestrous cycle. Of the total arachidonic acid in the uterus, $93 \%$ was esterified to uterine phospholipids, of which $80 \%$ was bound to phosphatidylcholine and phosphatidylethanolamine. There was a significant decrease in the quantity of arachidonic acid bound to phosphatidylcholine between Days 7 and 15 of the oestrous cycle. Less than $0.1 \%$ of the uterine arachidonic acid was present in the unesterified form. It is suggested that phosphatidylcholine may form the source of phosphatidyl for uterine prostaglandin synthesis in the guinea-pig.
\end{abstract}

\section{Introduction}

The substrates for prostaglandin (PG) synthesis are the C-20 poly-unsaturated fatty acids, namely 8,11,14-eicosatrienoic acid (C20:3), 5,8,11,14-eicosatetraenoic acid (arachidonic acid, C20:4) and 5,8,11,14,17-eicosapentaenoic acid (C20:5), which give rise to PGs of the 1, 2 and 3 series respectively. Generally, tissue levels of unesterified PG precursor fatty acids are low (Kunze \& Vogt, 1971; Haye \& Jacquemin, 1977), and stimulation of PG synthesis after addition of arachidonic acid or phospholipase $\mathrm{A}_{2}$ to perfusates or homogenates has been reported for several tissues, including the uterus (Eliasson, 1959; Vonkeman \& Van Dorp, 1968; Kunze \& Vogt, 1971; Sykes, Williams \& Rogers, 1975; Flower \& Blackwell, 1976). The availability of substrate to the PG synthetase enzymes therefore plays an important part in controlling the synthesis of PGS.

In this study, the distribution of arachidonic acid and other fatty acids among the major lipid classes of the uterus and plasma of the guinea-pig was investigated. Measurements were made on Days 7 and 15 of the oestrous cycle as these are days of low and high PGF- $2 \alpha$ synthesis by, and release from, the guinea-pig uterus (Poyser, 1972; Blatchley, Donovan, Horton \& Poyser, 1972; Earthy, Bishop \& Flack, 1975). A preliminary account of this work has been reported (Leaver \& Poyser, 1980).

\section{Materials and Methods}

\section{Sources of chemicals}

Lipids. Arachidonic acid (99\% pure, checked by t.l.c.), lipid standards for chromatography (mono-, di and tri-glycerides, and C16, C18 fatty acid methyl esters), cholesterol oleate, $\mathbf{L}-\boldsymbol{\alpha}$-phosphatidyl ethanolamine Type III, $\mathbf{L}-\boldsymbol{\alpha}$-phosphatidyl-L-serine; $\mathbf{L}$ - $\boldsymbol{\alpha}$-phosphatidyl inositol Grade III and L- $\alpha$-phosphatidyl choline Type VIIE were purchased from Sigma Chemical Co., Poole, England. Other standards for gas chromatography, i.e. a natural mixture of fatty acids 
from animal sources (PUFAI); C20 fatty acid methyl esters (GLC-60) and $n$-tricosanoic acid were purchased from Supelco Inc., Lower Bebington, England.

Chemicals. A Clinical Assay Set for the determination of cholesterol and the boron trifluoride-methanol complex were obtained from British Drug Houses, Poole, England. Triglyceride Diagnostic 405-B was purchased from Sigma, Poole, England.

Radiochemicals. $\left[5,6,8,9,11,12,14,15,{ }^{3} \mathrm{H}\right]$ Arachidonic acid (sp. act. $112 \mathrm{Ci} / \mathrm{mmol}$ ) was purchased from the Radiochemical Centre, Amersham, England.

Chromatographic materials. Silicic acid (100-200 mesh) was obtained from Unisil, Clarkson Chemical Company, Inc., Williamsport, U.S.A.; preparative thin-layer chromatography plates, covered with $0.25 \mathrm{~mm}$ silica gel, were from Merck, Darmstadt, Germany; gasliquid chromatography (g.l.c.) column packing SP-2330 (68\% cyanopropyl) and 100-200 mesh Chromosorb W-AW were purchased from Supelco, Inc. All solvents were of 'Analar' grade, and the $60-80^{\circ} \mathrm{C}$ boiling point fraction of petroleum spirit was always used.

\section{Animal studies}

Virgin guinea-pigs weighing $600-1000 \mathrm{~g}$ were examined daily and a vaginal smear taken when the vaginal membrane was perforate. The first day of the oestrous cycle was taken as the day before the post-ovulatory influx of leucocytes when cornification was maximal. All animals had exhibited at least 2 normal cycles before use.

Experiment 1. Guinea-pigs on Days 7 or 15 of the oestrous cycle were killed by cervical dislocation, and blood was collected into tubes (containing 10 units heparin/ml plasma) from the incised neck. Blood samples were centrifuged for $15 \mathrm{~min}$ at $1000 \mathrm{~g}$, and $10 \mathrm{ml}$ plasma withdrawn. Lipids were extracted by shaking the plasma with $25 \mathrm{ml}$ chloroform:methanol $(2: 1 \mathrm{v} / \mathrm{v})$ followed by centrifugation for $10 \mathrm{~min}$ at $1000 \mathrm{~g}$ and removal of the chloroform layer. The extraction was repeated twice, and the chloroform layers were pooled to give the total lipid extract. The uterus from each animal was rapidly removed, placed in a pre-weighed vial containing $5 \mathrm{ml}$ chloroform :methanol $(2: 1 \mathrm{v} / \mathrm{v})$ and the weight of the uterus was obtained. The uterus was homogenized in a glass homogenizer within $5 \mathrm{~min}$ of death. The homogenate was centrifuged for $15 \mathrm{~min}$ at $1000 \mathrm{~g}$, the supernatant was removed and the residue was re-extracted 3 more times, each with $15 \mathrm{ml}$ chloroform : methanol $(2: 1 \mathrm{v} / \mathrm{v})$. By adding $0.2 \mu \mathrm{Ci}\left[{ }^{3} \mathrm{H}\right]$ arachidonic acid to plasma and uterus before extraction it was found that $98 \pm 4 \%$ (s.e.m.) of $\left[{ }^{3} \mathrm{H}\right]$ arachidonic acid was extracted $(n=5)$.

The lipid extracts were subjected to one of the following procedures. (a) Lipid extracts of uterus and plasma were separated by silicic acid chromatography into fractions containing cholesterol ester, triglyceride, unesterified fatty acid (also containing diglyceride and monoglyceride) and phospholipid and $20 \%$ of each fraction was assayed for the appropriate lipid. The remaining $80 \%$ of each fraction was hydrolysed and the fatty acid content was determined by gas-liquid chromatography (g.l.c.). (b) Neutral lipids in uterine and plasma lipid extracts were separated by silicic acid chromatography. Unesterified fatty acid, diglyceride and monoglyceride were further separated by thin-layer chromatography (t.l.c.). Following hydrolysis, the arachidonic acid content in these 3 lipid classes was determined by g.l.c. (c) Uterine lipid extracts were separated into individual phospholipid classes by t.l.c., and the arachidonic acid content of the various phospholipids was determined by g.l.c.

Experiment 2. Guinea-pigs were killed on Day 7 of the oestrous cycle and the uterus removed. Endometrium was dissected from myometrium by cutting away $2 \times 4 \mathrm{~mm}$ sections of endometrium at $4^{\circ} \mathrm{C}$. Histological examination of samples of endometrium and myometrium indicated that at least $85 \%$ of the appropriate tissue was present in each fraction. The endometrial and myometrial fractions were each homogenized in $10 \mathrm{ml} 0.25 \mathrm{M}$-sucrose and lipids. were extracted as in Exp. 1(a). After hydrolysis, the content of PG precursor fatty acids was measured by g.l.c. 
For some animals, the endometrial fraction, following homogenization, was separated by differential centrifugation ( $12000 \mathrm{~g}$ for $10 \mathrm{~min}$, and $105000 \mathrm{~g}$ for $30 \mathrm{~min}$ ) into mitochondrial, microsomal and high-speed supernatant fractions. The mitochondrial and microsomal pellets were resuspended by homogenization in $10 \mathrm{ml} 0.25 \mathrm{M}$-sucrose. Part (10\%) of each fraction was taken for protein analysis by the method of Bradford (1976). The lipids in the remaining $90 \%$ were extracted as in Exp. 1(a) and after hydrolysis the content of PG precursor fatty acids was determined by g.l.c.

\section{Chromatography and assay procedures}

Silicic acid chromatography. Lipid extracts were taken to dryness, re-suspended in $3 \mathrm{ml}$ petroleum spirit, and applied to a silicic acid column $(1 \times 10 \mathrm{~cm})$ which had previously been dehydrated by elution with $150 \mathrm{ml}$ diethyl ether, $150 \mathrm{ml}$ diethyl ether: acetone $(1: 1 \mathrm{v} / \mathrm{v}), 150 \mathrm{ml}$ diethyl ether, and $200 \mathrm{ml}$ petroleum spirit at a rate of $1 \mathrm{ml} / \mathrm{min}$. The major lipid classes were eluted by solvents of increasing polarity in the following order: cholesterol ester by $200 \mathrm{ml}$ diethyl ether: petroleum spirit $(1: 100 \mathrm{v} / \mathrm{v})$; triglycerides by $150 \mathrm{ml}$ diethyl ether:petroleum spirit $(1: 25 \mathrm{v} / \mathrm{v})$; monoglyceride, diglyceride and unesterified fatty acid by $150 \mathrm{ml}$ diethyl ether; and phospholipid by $150 \mathrm{ml}$ methanol. The lipid extracted before chromatography and all column fractions after chromatography were analysed by each colorimetric method (see below). By comparing the results, it was found that more than $97 \%$ of phospholipid and $90 \%$ of the other lipid classes were eluted in the appropriate lipid fraction. Recovery of lipids after column chromatography ranged from $98 \%$ (phospholipid) to $75 \%$ (fatty acid).

Neutral lipids in Exp. 1(b) were obtained by eluting the silicic acid column only with $150 \mathrm{ml}$ diethyl ether.

Colorimetric analysis of total lipid. Cholesterol esters were assayed in terms of cholesterol concentration after hydrolysis using cholesterol oxidase (Clinical Assay Set). The crossreactivity of this method for other lipid classes was $<1 \%$. Triglyceride was analysed in terms of glycerol concentration using a triolein standard (Sigma Diagnostic Kit): there was a 20\% cross-reaction with phosphatidylcholine and $12 \%$ with arachidonic acid and cholesterol arachidonate. Unesterified fatty acid was determined by the method of Novak (1965), using arachidonic acid as the standard (cross-reactivity: phosphatidylcholine 20\%; cholesterol arachidonate $10 \%$; triglyceride $<1 \%$ ). Phospholipid was measured by the method of Raheja, Kaur, Singh \& Bhatia (1973) using L- $\alpha$-phosphatidyl choline as standard: the cross-reactivity with other lipids was $<1 \%$. Although some assays showed relatively high cross-reactivity for other lipids, this was not considered a problem since each lipid class was separated by silicic acid chromatography from the lipids which cross-react. All samples in each assay were assayed in duplicate and the mean value taken.

Assessment of accuracy and precision of colorimetric assays. Standard quantities of cholesterol $(0.05 \mathrm{mg})$, triolein $(0.75 \mathrm{mg})$, arachidonic acid $(0.01 \mathrm{mg})$ and phosphatidylcholine $(0.1 \mathrm{mg})$ were measured in the assays for cholesterol, triglyceride, unesterified fatty acid and phospholipid, respectively. Mean ( \pm s.e.m.) values $(\mathrm{mg})$ obtained were: cholesterol $0.050 \pm$ $0.0013(n=10)$, triolein $0.75 \pm 0.002(n=14)$, arachidonic acid $0.010 \pm 0.0003(n=11)$ and phosphatidylcholine $0.10 \pm 0.002(n=5)$. These values produce inter-assay coefficients of variation for their respective assays of $8,10,10$ and $4 \%$. The intra-assay coefficient of variation was obtained from calculating the variation between duplicate results for each biological sample assayed and the values obtained were: cholesterol assay $6 \%$, triglyceride assay $9 \%$, unesterified fatty acid $8 \%$ and phospholipid assay $6 \%$. These colorimetric assays were therefore considered to give sufficiently accurate and precise results.

Thin-layer chromatography (t.l.c.). (i) Monoglyceride, diglyceride and unesterified fatty acid in the neutral lipids eluted from the silicic acid column were separated by t.l.c. using 2 solvent systems. The first system of petroleum spirit:diethyl ether:acetic acid (75:25:1 by vol.) gave 
good separation of arachidonic acid from other neutral lipids. Diglyceride and monoglyceride, which ran close to the origin, were removed from the t.l.c. plate, extracted and re-chromatographed using the solvent system of chloroform:methanol:acetic acid (90:5:5 by vol.). Standards of monoglyceride, diglyceride and arachidonic acid were run simultaneously on each t.l.c. plate. (ii) Phospholipids in total uterine lipid extract were separated using the solvent system of chloroform :methanol:ammonia $(65: 35: 5$ by vol.). Standard phosphatidylcholine, phosphatidylserine, phosphatidylinositol and phosphatidylethanolamine were run simultaneously on each t.l.c. plate.

Lipids separated by solvent systems (i) and (ii) were visualized by exposure to iodine vapour. Areas corresponding to the $R_{\mathrm{F}}$ values of the standard lipids were scraped from the t.l.c. plate, and extracted 3 times, each with $10 \mathrm{ml}$ chloroform: methanol $(1: 1 \mathrm{v} / \mathrm{v})$.

Analysis of fatty acids by gas-liquid chromatography (g.l.c.). Lipid solutions, obtained following silicic acid chromatography or t.l.c. in Exp. 1 and solvent extraction in Exp. 2, were taken to dryness before addition of $2 \mathrm{ml} 0.5 \mathrm{M}-\mathrm{NaOH}$ in methanol and incubation for $10 \mathrm{~min}$ at $60^{\circ} \mathrm{C}$. After addition of $2.5 \mathrm{ml}$ boron trifluoride fatty acids were methylated by incubation for a further 5 min (Metcalfe, Schmitz \& Pelka, 1966). A known amount of the internal standard, the methyl ester of tricosanoic acid (C23:0), was added to each hydrolysate. Fatty acid methyl esters were extracted by shaking twice with $10 \mathrm{ml}$ petroleum spirit, in the presence of $2 \mathrm{ml}$ saturated sodium chloride solution.

Fatty acids were quantified by gas chromatography with flame ionization. The column, packed with 20\% Supelco SP-2330 on 100-120 mesh Chromosorb W-AW, was $3 \mathrm{~m} \times 4 \mathrm{~mm}$ Pyrex glass, and the injector and column temperatures were maintained at 300 and $189^{\circ} \mathrm{C}$ respectively. Standard fatty acid methyl esters were analysed by g.l.c. and a graph was drawn of log retention time of each fatty acid divided by log retention time of internal standard, versus carbon number. Each sample $(2.5 \mu \mathrm{l})$ was injected into the g.l.c., and by calculating log retention time of fatty acid peaks divided by log retention time of internal standard, and by reference to the standard graph, the identity of fatty acids in the extract was established. The proportion of each fatty acid was determined by calculating each peak area with a computing integrator and dividing by the total area of identified peaks, excluding the internal standard. Samples were assayed in duplicate and the mean coefficient of variation between paired values was $7 \%$. If the variation between paired values was greater than $15 \%$, the sample was reassayed in duplicate.

The amount of arachidonic acid in lipid fractions was calculated from the ratio of peak areas of arachidonic acid to internal standard in relation.to a standard curve of the ratios of peak areas of known amounts of arachidonic acid to internal standard. Standard arachidonic acid $(100 \mu \mathrm{g})$, measured by the g.l.c. assay, gave a mean \pm s.e.m. value of $101 \pm 4.6(n=6)$, producing an inter-assay coefficient of variation of 9\%. In Exp. 2, the quantities of C20:3 and C20:5 were similarly calculated by reference to the standard curve for arachidonic acid because in control experiments the standard curves of C20:3, C20:4 and C20:5 were superimposable.

\section{Statistical tests}

Results, expressed as mean \pm s.e.m., were analysed by Student's $t$ test for paired or unpaired data, as appropriate.

\section{Results}

\section{Experiment 1}

The major lipid classes in both guinea-pig uterus and plasma were triglyceride and phospholipid (Table 1). Only low concentrations of cholesterol ester and unesterified fatty acid were present. There was a significant $(P<0.025)$ decrease in uterine triglyceride on Day 15 , 
compared with Day 7, of the oestrous cycle. The concentrations of other lipid classes in the uterus and plasma did not differ significantly between Days 7 and 15 .

Table 1. Quantities of the different lipid classes in guinea-pig uterus and plasma on Days 7 and 15 of the oestrous cycle

\begin{tabular}{llclcc}
\hline & \multicolumn{2}{c}{ Uterus $(\mathrm{mg} / \mathrm{g})$} & & \multicolumn{2}{c}{ Plasma $(\mathrm{mg} / \mathrm{ml})$} \\
\cline { 2 - 3 } \cline { 5 - 6 } \multicolumn{1}{c}{ Lipid class } & \multicolumn{1}{c}{ Day 7 } & Day 15 & & Day 7 & Day 15 \\
\hline Cholesterol ester & $0.33 \pm 0.21(6)$ & $0.19 \pm 0.08(5)$ & & $0.04 \pm 0.01(6)$ & $0.03 \pm 0.02(6)$ \\
Triglyceride & $12.4 \pm 2.3(4)$ & $5.2 \pm 1.3(5)^{*}$ & & $0.24 \pm 0.09(4)$ & $0.46 \pm 0.10(5)$ \\
Unesterified fatty acid & $0.25 \pm 0.07(7)$ & $0.15 \pm 0.03(5)$ & & $0.02 \pm 0.01(6)$ & $0.03 \pm 0.01(4)$ \\
Phospholipid & $13.3 \pm 1.4(8)$ & $12.1 \pm 1.1(6)$ & & $0.22 \pm 0.03(6)$ & $0.15 \pm 0.03(5)$ \\
\hline
\end{tabular}

Values are mean \pm s.e.m. for the no. of determinations in parentheses.

* Significantly different from corresponding Day 7 value $(P<0.025)$.

The percentage composition of fatty acids esterified to the different lipid classes in the uterus and plasma are shown in Tables 2 and 3 . In addition to the fatty acids listed, compounds with a retention time equivalent to the uneven-numbered saturated fatty acids, $n$-pentadecanoic (C 15:0), and $n$-heptadecanoic (C17:0) acid, were detected, but represented $<1 \%$ of the total fatty acid in uterine and plasma cholesterol ester, triglyceride and phospholipid. Of the 3 PG precursor fatty acids, arachidonic acid was the most abundant in all lipid classes. Eicosatrienoic acid (C20:3) was esterified almost exclusively to plasma and uterine triglyceride and represented $20-30 \%$ of PG precursor fatty acid in this lipid class.

Table 2. Mean percentage ( \pm s.e.m. for 8 observations) composition of fatty acids in uterine lipids on Days 7 and 15 of the oestrous cycle in guinea-pigs

\begin{tabular}{|c|c|c|c|c|c|c|c|c|}
\hline \multirow{2}{*}{$\begin{array}{l}\text { Fatty } \\
\text { acid } \dagger\end{array}$} & \multicolumn{2}{|c|}{ Cholesterol ester } & \multicolumn{2}{|c|}{ Triglyceride } & \multicolumn{2}{|c|}{$\begin{array}{l}\text { Diglyceride, monoglyceride, } \\
\text { unesterified fatty acid }\end{array}$} & \multicolumn{2}{|c|}{ Phospholipid } \\
\hline & Day 7 & Day 15 & Day 7 & Day 15 & Day 7 & Day 15 & Day 7 & Day 15 \\
\hline $\begin{array}{l}16: 0 \\
16: 1\end{array}$ & $\begin{array}{c}37.0 \pm 2.2^{*} \\
3.5 \pm 2.5\end{array}$ & $\begin{array}{r}24 \cdot 3 \pm 4 \cdot 3 \\
7 \cdot 7 \pm 3 \cdot 4\end{array}$ & $\begin{array}{r}40.5 \pm 3.0 \\
2 \cdot 1 \pm 0.5^{*}\end{array}$ & $\begin{array}{r}35.0 \pm 6.3 \\
4.2 \pm 0.6\end{array}$ & $\begin{array}{r}34.1 \pm 3.7 \\
1.1 \pm 0.8\end{array}$ & $\begin{array}{r}28.5 \pm 4.8 \\
2.7 \pm 1.5\end{array}$ & $\begin{array}{r}25.2 \pm 1.5 \\
0.5 \pm 0.3\end{array}$ & $\begin{array}{r}22.2 \pm 0.9 \\
1.0 \pm 0.8\end{array}$ \\
\hline $\begin{array}{l}18: 0 \\
18: 1 \\
18: 2 \\
18: 3\end{array}$ & $\begin{array}{r}20.8 \pm 2.1 \\
18.4 \pm 8.9 \\
9.9 \pm 2.6 \\
3.9 \pm 2.9\end{array}$ & $\begin{array}{r}22.1 \pm 2.9 \\
17 \cdot 7 \pm 5 \cdot 8 \\
17 \cdot 1 \pm 5.7 \\
2.4 \pm 1.3\end{array}$ & $\begin{array}{c}10.5 \pm 0.5^{*} \\
27.4 \pm 4.4 \\
8.6 \pm 1.6^{*} \\
6.1 \pm 1.5\end{array}$ & $\begin{array}{r}7.4 \pm 1 \cdot 1 \\
25 \cdot 5 \pm 1 \cdot 6 \\
13.6 \pm 1 \cdot 3 \\
7.9 \pm 1.5\end{array}$ & $\begin{array}{c}17.1 \pm 3.9 \\
12.5 \pm 1.6^{*} \\
8.2 \pm 1.8 \\
0.3 \pm 0.2\end{array}$ & $\begin{array}{r}19.8 \pm 5.2 \\
17.5 \pm 1.2 \\
10.6 \pm 1.2 \\
0.2 \pm 0.2\end{array}$ & $\begin{array}{r}21.2 \pm 2.6 \\
20.3 \pm 3 \cdot 0 \\
11.3 \pm 1.3 \\
0.7 \pm 0.4\end{array}$ & $\begin{array}{r}21.2 \pm 4.3 \\
19.3 \pm 1.1 \\
12.4 \pm 1.3 \\
0.3 \pm 0.1\end{array}$ \\
\hline $\begin{array}{c}20: 0 \\
+ \\
20: 1\end{array}$ & $4 \cdot 1 \pm 3 \cdot 6$ & $9 \cdot 1 \pm 3 \cdot 5$ & $0.6 \pm 0.2$ & $1.9 \pm 0.7$ & $2 \cdot 1 \pm 0.9$ & $1.1 \pm 0.8$ & $0.8 \pm 0.2$ & $0.4 \pm 0.2$ \\
\hline $\begin{array}{l}20: 2 \\
20: 3 \\
20: 4 \\
20: 5\end{array}$ & $\begin{array}{l}0.7 \pm 0.1^{*} \\
0.1 \pm 0.04 \\
4.9 \pm 2.9 \\
0.4 \pm 0.4\end{array}$ & $\begin{array}{c}0.04 \pm 0.04 \\
1.1 \pm 0.1 \\
7.6 \pm 2.5 \\
<0.02\end{array}$ & $\begin{array}{l}0.3 \pm 0.1 \\
0.5 \pm 0.2 \\
1.6 \pm 0.6 \\
0.2 \pm 0.1\end{array}$ & $\begin{array}{l}0.3 \pm 0.1 \\
0.6 \pm 0.4 \\
2.1 \pm 1.3 \\
0.2 \pm 0.1\end{array}$ & $\begin{array}{c}0.5 \pm 0.3 \\
<0.02 \\
10.3 \pm 1.8 \\
0.3 \pm 0.2\end{array}$ & $\begin{array}{c}0.6 \pm 0.3 \\
<0.02 \\
9.5 \pm 2.2 \\
0.6 \pm 0.3\end{array}$ & $\begin{array}{c}0.6 \pm 0.2 \\
<0.02 \\
17.0 \pm 1.9 \\
0.3 \pm 0.2\end{array}$ & $\begin{array}{c}0.6 \pm 0.1 \\
0.03 \pm 0.03 \\
19.2 \pm 1.6 \\
<0.02\end{array}$ \\
\hline
\end{tabular}

* Significantly different $(P<0.05)$ from Day 15 value for that lipid.

$\dagger 16: 0$, palmitic; $16: 1$, palmitoleic; 18:0, stearic; $18: 1$, oleic; 18:2, linoleic; 18:3, $\alpha$-linolenic; 20:0; arachidic; 20:1, eicosenoic; $20: 2$, eicosadienoic; $20: 3$, eicosatrienoic; $20: 4$, arachidonic; $20: 5$, eicosapentaenoic.

In the uterus, the percentage composition of the unsaturated fatty acids (C16:1 and C18:1) and of the less saturated fatty acids $(\mathrm{C} 16: 0, \mathrm{C} 18: 0)$ tended to increase while the percentage composition of C20:2 tended to decrease on Day 15 in comparison with Day 7. A similar trend occurred in the $\mathrm{C} 18$ fatty acids of plasma cholesterol ester and triglyceride, which showed an increase in C18:1 and a decrease in C18:0, respectively. However, an increase in plasma cholesterol ester C16:0 contrasted with the decrease in concentration of this fatty acid in uterine cholesterol ester. 
Table 3. Mean percentage ( \pm s.e.m. for 8 observations) composition of fatty acids in plasma lipids on Days 7 and 15 of the oestrous cycle in guinea-pigs

\begin{tabular}{|c|c|c|c|c|c|c|c|c|}
\hline \multirow{2}{*}{$\begin{array}{l}\text { Fatty } \\
\text { acid } \dagger\end{array}$} & \multicolumn{2}{|c|}{ Cholesterol ester } & \multicolumn{2}{|c|}{ Triglyceride } & \multicolumn{2}{|c|}{$\begin{array}{l}\text { Diglyceride, monoglyceride } \\
\text { unesterified fatty acid }\end{array}$} & \multicolumn{2}{|c|}{ Phospholipid } \\
\hline & Day 7 & Day 15 & Day 7 & Day 15 & Day 7 & Day 15 & Day 7 & Day 15 \\
\hline $\begin{array}{l}16: 0 \\
16: 1\end{array}$ & $\begin{array}{c}12.3 \pm 3.5^{*} \\
3.1 \pm 1.4\end{array}$ & $\begin{array}{r}24 \cdot 6 \pm 1 \cdot 1 \\
5 \cdot 5 \pm 2.9\end{array}$ & $\begin{array}{r}35 \cdot 0 \pm 3 \cdot 2 \\
2 \cdot 1 \pm 1 \cdot 2\end{array}$ & $\begin{array}{r}29.9 \pm 3.0 \\
2 \cdot 1 \pm 1.4\end{array}$ & $\begin{array}{c}32.8 \pm 2.7 \\
1.0 \pm 0.6^{*}\end{array}$ & $\begin{array}{r}29.7 \pm 2.2 \\
3.5 \pm 0.5\end{array}$ & $\begin{array}{r}21.9 \pm 2.3 \\
1.6 \pm 1.6\end{array}$ & $\begin{array}{r}22.6 \pm 2.1 \\
2.7 \pm 1.0\end{array}$ \\
\hline $\begin{array}{l}18: 0 \\
18: 1 \\
18: 2 \\
18: 3\end{array}$ & $\begin{array}{c}21.5 \pm 20.2 \\
10.3 \pm 0.4^{* *} \\
43.8 \pm 7.4 \\
6.6 \pm 2.5\end{array}$ & $\begin{array}{r}7.5 \pm 0.9 \\
14.2 \pm 1.1 \\
36.8 \pm 8.4 \\
6.0 \pm 2.3\end{array}$ & $\begin{array}{r}15.0 \pm 2.0^{*} \\
18.6 \pm 2.4 \\
23.0 \pm 2.8 \\
9.0 \pm 2.4\end{array}$ & $\begin{array}{r}7.7 \pm 2.3 \\
22.5 \pm 2.2 \\
19.9 \pm 4.4 \\
8.4 \pm 2.7\end{array}$ & $\begin{array}{r}19.4 \pm 6.2 \\
14.5 \pm 4 \cdot 1 \\
18.3 \pm 2.8 \\
8.9 \pm 2.3\end{array}$ & $\begin{array}{r}7.3 \pm 2.1 \\
21.9 \pm 1.6 \\
21.0 \pm 4.1 \\
11.3 \pm 1.6\end{array}$ & $\begin{array}{r}23.0 \pm 3.9 \\
15.9 \pm 4.2 \\
26.0 \pm 3.7 \\
2.6 \pm 0.9\end{array}$ & $\begin{array}{r}23.5 \pm 4.7 \\
12.2 \pm 2.6 \\
18.4 \pm 3.0 \\
3.4 \pm 1.3\end{array}$ \\
\hline $\begin{array}{c}20: 0 \\
+ \\
20: 1\end{array}$ & $0.1 \pm 0.1$ & $4 \cdot 1 \pm 3 \cdot 4$ & $1 \cdot 0 \pm 0.3$ & $3.9 \pm 1.8$ & $1.1 \pm 0.7$ & $2 \cdot 6 \pm 1 \cdot 3$ & $0.3 \pm 0.2$ & $1.0 \pm 0.4$ \\
\hline $\begin{array}{l}20: 2 \\
20: 3 \\
20: 4 \\
20: 5\end{array}$ & $\begin{array}{c}0.1 \pm 0.1 \\
<0.02 \\
3.7 \pm 2.8 \\
0.3 \pm 0.2\end{array}$ & $\begin{array}{c}0.1 \pm 0.1 \\
<0.02 \\
6.1 \pm 2.3 \\
0.1 \pm 0.1\end{array}$ & $\begin{array}{l}0.1 \pm 0.1 \\
0.9 \pm 0.5 \\
2.5 \pm 1.3 \\
0.4 \pm 0.1\end{array}$ & $\begin{array}{l}0.2 \pm 0.1 \\
1.2 \pm 1.0 \\
3.2 \pm 2.5 \\
1.0 \pm 0.8\end{array}$ & $\begin{array}{c}0.06 \pm 0.04 \\
<0.02 \\
1.8 \pm 0.8 \\
0.4 \pm 0.3\end{array}$ & $\begin{array}{l}0.3 \pm 0.3 \\
<0.02 \\
0.6 \pm 0.3 \\
0.6 \pm 0.3\end{array}$ & $\begin{array}{c}0.5 \pm 0.3 \\
<0.02 \\
5.3 \pm 0.9 \\
0.2 \pm 0.1\end{array}$ & $\begin{array}{c}0.3 \pm 0.9 \\
<0.02 \\
7.8 \pm 2.3 \\
0.5 \pm 0.3\end{array}$ \\
\hline
\end{tabular}

Significantly different $\left({ }^{*} P<0.05 ; * * P<0.02\right)$ from Day 15 value for that lipid.

$\dagger 16: 0$, palmitic; 16:1, palmitoleic; 18:0, stearic; 18:1, oleic; 18:2, linoleic; 18:3, $\alpha$-linolenic; 20:0, arachidic; 20:1, eicosenoic; 20:2, eicosadienoic; $20: 3$, eicosatrienoic; $20: 4$ ar achidonic; $20: 5$, eicosapentaenoic.

The mean ratio between uterine and plasma fatty acids in 3 lipid classes, calculated from each animal, is shown in Table 4. The plasma to uterus fatty acid ratios in each lipid class were not significantly different when Days 7 and 15 were compared, suggesting that uterine uptake of plasma fatty acids did not fluctuate during the oestrous cycle. Day 7 and 15 results were therefore combined. Arachidonic acid (C20:4) was more concentrated in uterine than in plasma phospholipid. However, the proportion of arachidonic acid in cholesterol ester was similar in plasma and uterus, and uterine triglycerides contained a smaller proportion of arachidonic acid than did plasma triglycerides. The proportion of the $\mathrm{C} 18$ fatty acids, linoleic $\mathrm{C}(18: 2)$ and linolenic (18:3), was always lower in uterine than plasma lipids.

Table 4. Mean ratios ( \pm s.e.m.) of fatty acid composition in lipids in the plasma and uterus of the same guinea-pig using the data in Tables 2 and 3 and combining the results for Days 7 and 15

(see text)

\begin{tabular}{lccc}
\hline & \multicolumn{3}{c}{ Ratio between plasma and uterus } \\
\cline { 2 - 4 } \multicolumn{1}{c}{ Fatty acid } & Cholesterol ester & Triglyceride & Phospholipid \\
\hline $16: 0$ & $0.98 \pm 0.55$ & $0.85 \pm 0.08$ & $1.04 \pm 0.07$ \\
$16: 1$ & $1.54 \pm 0.63$ & $1.96 \pm 1.11$ & $4.25 \pm 2.8$ \\
$18: 0$ & $0.42 \pm 0.15$ & $1.10 \pm 0.20$ & $1.01 \pm 0.12$ \\
$18: 1$ & $1.82 \pm 0.86$ & $1.03 \pm 0.17$ & $0.76 \pm 0.10$ \\
$18: 2$ & $10.14 \pm 5.10$ & $2.18 \pm 0.39$ & $2.06 \pm 0.26$ \\
$18: 3$ & $2.37 \pm 1.09$ & $1.52 \pm 0.40$ & $13.32 \pm 5.60$ \\
$20: 0+20: 1$ & $0.63 \pm 0.28$ & $2.28 \pm 1.51$ & $3.45 \pm 1.54$ \\
$20: 2$ & $1.17 \pm 0.17$ & $0.92 \pm 0.28$ & $0.52 \pm 0.08$ \\
$20: 4$ & $0.91 \pm 0.17$ & $1.21 \pm 0.27$ & $0.36 \pm 0.04$ \\
\hline
\end{tabular}

Uterine phospholipids contained $93 \%$ of the total arachidonic acid (Table 5). The remaining $7 \%$ of arachidonic acid was distributed among other lipids in the following order: triglyceride $>$ cholesterol ester $>$ unesterified acid $=$ diglyceride $>$ monoglyceride. Only $47 \%$ of the arachidonic acid in the plasma was bound to phospholipid. Cholesterol ester and triglyceride contained $20 \%$ and $28 \%$ of plasma arachidonic acid respectively. The content of arachidonic acid in unesterified fatty acid, monoglyceride and diglyceride in plasma was low. 


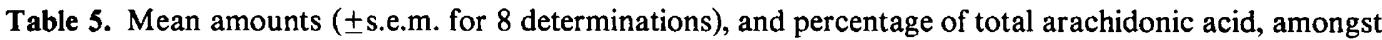
uterine and plasma lipids in the guinea-pig on Days 7 and 15 of the oestrous cycle

\begin{tabular}{|c|c|c|c|c|}
\hline \multirow[b]{2}{*}{ Lipid class } & \multicolumn{2}{|c|}{ Uterus ( $\mu \mathrm{g} / \mathrm{g}$ wet weight) } & \multicolumn{2}{|c|}{ Plasma $(\mu \mathrm{g} / \mathrm{ml})$} \\
\hline & $\begin{array}{c}\text { Day } 7 \\
\text { (\% of total) }\end{array}$ & $\begin{array}{c}\text { Day } 15 \\
\text { (\% of total) }\end{array}$ & $\begin{array}{c}\text { Day } 7 \\
\text { (\% of total) }\end{array}$ & $\begin{array}{c}\text { Day } 15 \\
\text { (\% of total) }\end{array}$ \\
\hline Cholesterol ester & $12.1 \pm 8.5(1.2)$ & $24.5 \pm 13.8(2.2)$ & $1.35 \pm 0.43(16.9)$ & $3.04 \pm 1.46(22.2)$ \\
\hline Triglyceride & $57.1 \pm 18.0(5.4)$ & $58.6 \pm 21.5(5.2)$ & $2.29 \pm 1.36(28.6)$ & $3.87 \pm 1.12(28.2)$ \\
\hline Unesterified fatty acid & $0.95 \pm 0.34(0.09)$ & $1.34 \pm 0.45(0.12)$ & $0.15 \pm 0.06(1.9)$ & $0.22 \pm 0.10(1.6)$ \\
\hline Diglyceride & $0.85 \pm 0.58(0.08)$ & $1.29 \pm 0.84(0.11)$ & $0.07 \pm 0.03(0.9)$ & $0.05 \pm 0.02(0.4)$ \\
\hline Monoglyceride & $0.50 \pm 0.12(0.05)$ & $0.57 \pm 0.22(0.05)$ & $0.24 \pm 0.03(3.0)$ & $0.19 \pm 0.04(1.4)$ \\
\hline Phospholipid & $979 \pm 191(93.1)$ & $1043 \pm 231(92.4)$ & $3.90 \pm 0.98(48.8)$ & $6.34 \pm 0.94(46.2)$ \\
\hline
\end{tabular}

Phosphatidylcholine and phosphatidylethanolamine contained $80 \%$ of the arachidonic acid bound to phospholipids in the uterus (Table 6). There was a significant $(P<0.05)$ decrease in the amount of arachidonic acid esterified to phosphatidylcholine on Day 15 of the oestrous cycle.

Table 6. Mean concentration ( \pm s.e.m. of 4 determinations) of arachidonic acid in uterine phospholipids on Days 7 and 15 of the oestrous cycle in the guinea-pig

\begin{tabular}{cccc}
\hline & \multicolumn{3}{c}{ Amount of arachidonic acid bound ( $\mu \mathrm{g} / \mathrm{g}$ uterus) } \\
\cline { 2 - 4 } $\begin{array}{c}\text { Day of } \\
\text { cycle }\end{array}$ & $\begin{array}{c}\text { Phosphatidyl- } \\
\text { ethanolamine }\end{array}$ & $\begin{array}{c}\text { Phosphatidyl- } \\
\text { choline }\end{array}$ & $\begin{array}{c}\text { Phosphatidylserine and } \\
\text { phosphatidylinositol }\end{array}$ \\
\hline 7 & $738 \pm 131$ & $452 \pm 43^{*}$ & $172 \pm 68$ \\
15 & $529 \pm 57$ & $249 \pm 32$ & $197 \pm 64$ \\
\hline
\end{tabular}

* Significantly different $(P<0.05)$ from Day 15 value.

\section{Experiment 2}

The concentrations of total arachidonic acid (C20:4) in the endometrium and myometrium were similar (Table 7), and were very much higher than the concentrations of eicosatrienoic acid (C20:3) and eicosapentanoic acid (C20:5) which were present predominantly in the myometrium. Arachidonic acid was found at a concentration of $45-55 \mu \mathrm{g} / \mathrm{mg}$ protein in each subcellular fraction investigated.

Table 7. Mean amounts ( \pm s.e.m. for 4 observations) of prostaglandin fatty acid precursors in myometrium and endometrium and in endometrial subcellular fractions (Fraction $1,600 \mathrm{~g}, 10 \mathrm{~min}, 12000 \mathrm{~g}$, $10 \mathrm{~min}$, pellet; Fraction $2,12000 \mathrm{~g}, 10 \mathrm{~min}, 105000 \mathrm{~g}, 30 \mathrm{~min}$, pellet; Fraction 3, $105000 \mathrm{~g}, 30 \mathrm{~min}$, supernatant) on Day 7 of the oestrous cycle

\begin{tabular}{|c|c|c|c|c|c|c|c|}
\hline \multirow[b]{2}{*}{ Uterine tissue } & \multicolumn{3}{|c|}{$\begin{array}{c}\text { Fatty acid content } \\
(\mu \mathrm{g} / \mathrm{g} \text { wet weight tissue })\end{array}$} & \multirow{2}{*}{$\begin{array}{l}\text { Endometrial } \\
\text { fraction }\end{array}$} & \multicolumn{3}{|c|}{$\begin{array}{l}\text { Fatty acid content } \\
(\mu \mathrm{g} / \mathrm{mg} \text { protein })\end{array}$} \\
\hline & $\mathrm{C} 20: 3$ & $\mathrm{C} 20: 4$ & C20:5 & & $\mathrm{C} 20: 3$ & $\mathrm{C} 20: 4$ & $\mathrm{C} 20: 5$ \\
\hline $\begin{array}{l}\text { Myometrium } \\
\text { Endometrium }\end{array}$ & $\begin{array}{l}8 \cdot 8 \pm 2 \cdot 5 \\
>0 \cdot 1\end{array}$ & $\begin{array}{l}210 \pm 99 \\
165 \pm 23\end{array}$ & $\begin{array}{c}4.8 \pm 2.5 \\
0.12 \pm 0.07\end{array}$ & $\begin{array}{l}1 \\
2 \\
3\end{array}$ & $\begin{array}{l}>0.01 \\
>0.01 \\
>0.01\end{array}$ & $\begin{array}{l}45 \pm 10 \\
56 \pm 7 \\
56 \pm 3\end{array}$ & $\begin{array}{c}>0.1 \\
0.28 \pm 0.15 \\
>0.1\end{array}$ \\
\hline
\end{tabular}

\section{Discussion}

The output of PGF-2 $\alpha$ from the guinea-pig uterus has been shown to vary 10-20-fold during the oestrous cycle (Blatchley et al., 1972; Earthy et al., 1975), although fluctuations 
of only 2-3-fold in the activity of the PG synthetase enzyme have been reported during the guinea-pig oestrous cycle (Poyser, 1972; Wlodawer, Kindahl \& Hamberg, 1976). This suggests that the synthesis of PGF- $2 \alpha$ by, and release from, the guinea-pig uterus, although dependent upon an increase in PG synthetase levels (Poyser, 1979), are also controlled by other factors, some of which may control substrate availability.

Unesterified arachidonic acid represented only $0.1 \%$ of the total arachidonic acid content of the uterus (Table 5). In other tissues, low levels of unesterified arachidonic acid have been reported (Kunze \& Vogt, 1971; Haye \& Jacquemin, 1977), at concentrations close to the limit of detection of g.l.c. $(0.2 \mu \mathrm{g})$. However, even $1 \mu \mathrm{g}$ unesterified arachidonic acid/g represents a considerable pool in relation to uterine PG production. The homogenized guinea-pig uterus on Day 15 synthesizes approximately $1.2 \mu \mathrm{g} \mathrm{PGF}-2 \alpha / \mathrm{g}$ uterus during incubation (Poyser, 1972 ), indicating a $0.1 \%$ conversion of total uterine arachidonic acid. Whether the rapid postmortem release of arachidonic acid reported in other tissues (Flower \& Blackwell, 1976; Marion, Pappius \& Wolfe, 1979) occurs in the uterus is not known. But even if the uterine concentration of unesterified arachidonic acid in vivo is as high as the $1 \mu \mathrm{g} / \mathrm{ml}$ that we found, it must be replenished from some other source (intracellular esters or by uptake from the plasma) to maintain PG synthesis.

Arachidonic acid was widely distributed within the tissues and subcellular fractions of the uterus (Table 7). However, PGs are synthesized mainly by the endometrium (Thorburn \& Challis, 1979) and PG synthetase has been detected in several subcellular fractions of the endometrium (Wlodawer et al., 1976). The site of PG synthesis is important in relation to the subcellular localization of substrate, and in this study, the precursor fatty acids of the 1- and 3series were found predominantly in the myometrium, although in much lower concentrations than was arachidonic acid. This presumably explains why the uterus synthesizes PGs of the 2series (Blatchley et al., 1972; Poyser, 1972).

The source of arachidonic acid for uterine PG synthesis is still a matter for conjecture. In women, there is evidence of lysosome-mediated release of phospholipases into the amniotic fluid during parturition (Gustavii, 1972; Liggins, Foster, Grieves \& Schwatz, 1977), suggesting that phospholipids represent a source of arachidonic acid for PG synthesis. Triglyceride-rich lipid droplets, which accumulate in the uterus during dioestrus and pregnancy in animals of several species, and which are depleted at oestrus (Beall, 1972), have also been suggested as an arachidonic acid source (Brinsfield \& Hawk, 1973; Thorburn \& Challis, 1979). Our study showed that phospholipids were the major source $(93 \%)$ of arachidonic acid within the uterus, with depletion of the amount of arachidonic acid bound to phosphatidylcholine occurring on Day 15 of the oestrous cycle (Tables 5 and 6). It is therefore possible that phosphatidylcholine represents a source of arachidonic acid for PG synthesis. Two lines of evidence support the theory of a phospholipid precursor of uterine PGs. Firstly, arachidonic acid release from guinea-pig uterine homogenates is inhibited by the phospholipase $\mathrm{A}_{2}$ inhibitor, $p$-bromophenacyl bromide (Mitchell, Poyser \& Wilson, 1977). Secondly, incubation of human endometrium with phospholipase $\mathrm{A}_{2}$ stimulates PG production by this tissue (Sykes et al., 1975).

A significant depletion of triglyceride in the guinea-pig uterus was observed between Days 7 and 15 (Table 1). However, the amount of arachidonic acid bound triglyceride on Days 7 and 15 did not change (Table 5), indicating enrichment of triglycerides with arachidonic acid between these days. Rapid turnover of such a relatively small pool of arachidonic acid would be required if triglyceride were to represent the principal pool of PG precursor. The turnover of arachidonic acid bound to triglyceride during the oestrous cycle would therefore merit further investigation.

The contribution of plasma lipids to uterine lipid metabolism is not known. The uterus is active in the synthesis of fatty acids and their incorporation into lipids in mice (Emmelot \& Bosch, 1954), rat, rabbits and man (Beall, 1972) and oestrogen has been reported to increase these processes. The high concentration of arachidonic acid in the phospholipids of the guineapig uterus suggests either that the uterus is capable of specific uptake of arachidonic acid, or, 
more probably, that enzymes capable of synthesizing arachidonic acid are present in the uterus. The ratio of plasma/uterine fatty acid composition of the major lipids was not significantly different on Days 7 and 15 (Table 4), indicating that there had been no changes of $>15 \mu \mathrm{g}$ fatty acid in specific uptake of arachidonic acid by the uterus or in general uptake of plasma lipid in the pools examined on Days 7 and 15.

In any study of the availability of arachidonic acid for prostaglandin synthesis, it is important to investigate the flux of arachidonic acid in the various lipid pools. Accordingly, we are now using radiolabelled arachidonic acid to investigate this flux during the oestrous cycle.

These studies were supported by grants from the M.R.C. and The Wellcome Trust.

\section{References}

Beall, J.R. (1972) Uterine lipid metabolism-A review of the literature. Comp. Biochem. Physiol. 42, 175195.

Blatchley, F.R., Donovan, B.T., Horton, E.W. \& Poyser, N.L. (1972) The release of prostaglandins and progestins into the utero-ovarian venous blood of guinea-pigs during the oestrous cycle and following oestrogen treatment. $J$. Physiol., Lond. 228, 69-88.

Bradford, M.M. (1976) A rapid and sensitive method for the quantitation of microgram quantities of protein utilizing the principle of protein-dye binding. Analyt. Biochem. 72, 248-254.

Brinsfield, T.H. \& Hawk, H.W. (1973) Control by progesterone of the concentration of lipid droplets in epithelial cells of sheep endometrium. J. Anim. Sci. 36, 919-922.

Earthy, M., Bishop, C. \& Flack, J.D. (1975) Progesterone and prostaglandin $F$ concentration in utero-ovarian venous plasma of cyclic guinea-pigs. J. Endocr. 64, $11 \mathrm{P}$.

Eliasson, R. (1959) Prostaglandin occurrence, formation and biological actions. Acta physiol. scand., Suppl. 46, 158-161.

Emmelot, P. \& Bosch, L. (1954) The influence of oestrogens on the protein and lipid metabolism of the mouse uterus studied with acetate-1-C ${ }^{14}$. Recl Trav. chim. Pays-Bas Belg. 73, 874-877.

Flower, R.J. \& Blackwell, G.J. (1976) The importance of phospholipase- $\mathbf{A}_{2}$ in prostaglandin biosynthesis. Biochem. Pharmac. 25, 285-291.

Gustavii, B. (1972) A histological study on the effect on the placenta of intra-amniotically and extraamniotically injected hypotonic saline in therapeutic abortion. Acta obstet. gynec. scand. 51, 121-125.

Haye, B. \& Jacquemin, C. (1977) Incorporation of $\left[{ }^{14} \mathrm{C}\right.$ ]arachidonate in pig thyroid lipids and prostaglandins. Biochim. Biophys. Acta 487, 231-242.

Kunze, H. \& Vogt, W. (1971) Significance of phospho lipase A for prostaglandin formation. Ann. N.Y. Acad. Sci. 180, 123-125.

Leaver, H.A. \& Poyser, N.L. (1980) Arachidonic acid in guinea-pig uterus and plasma. Adv. Prostaglandin Thromboxane Res. 8, 1361-1363.
Liggins, G.C., Foster, C.S., Grieves, S.A. \& Schwatz, A.L. (1977) Control of parturition in man. Biol. Reprod. 16, 39-56.

Marion, J., Pappius, H.M. \& Wolfe, L.S. (1979) Evidence for the use of a pool of free arachidonic acid in rat cerebral cortex tissue for prostaglandin $\mathrm{F}_{2} \alpha$ synthesis in vitro. Biochim. Biophys. Acta 573, 229-237.

Metcalfe, L.D., Schmitz, A.A. \& Pelka, J.R. (1966) Rapid preparation of fatty acid esters for gas chromatographic analysis. Analyt. Chem. 38, 514 515 .

Mitchell, S., Poyser, N.L. \& Wilson, N.H. (1977) Effect of p-bromophenacyl bromide, an inhibitor of phospholipase $\mathbf{A}_{2}$, on arachidonic acid and prostaglandin synthesis by the guinea-pig uterus, in vitro. Br. J. Pharmac. 59, 107-113.

Novak, M. (1965) Colorimetric ultramicro method for the determination of free fatty acids. J. Lipid Res. 6, 431-433.

Poyser, N.L. (1972) Production of prostaglandins by the guinea-pig uterus. $J$. Endocr. 54, 147-159.

Poyser, N.L. (1979) Effect of actinomycin D on uterine prostaglandin production and oestrous cycle length in guinea-pigs. J. Reprod. Fert. 56, 559-565.

Raheja, R.K., Kaur, C., Singh, A. \& Bhatia, I.S. (1973) New colorimetric method of determination of phospholipids without acid digestion. J. Lipid Res. 14, 695-697.

Sykes, J.A.C., Williams, K.I. \& Rogers, A.F. (1975) Prostaglandin production and metabolism by homogenates of pregnant human deciduum and myo metrium. J. Endocr. 64, 18P-19P.

Thorburn, G.D. \& Challis, J.R.G. (1979) Endocrine control of parturition. Physiol. Rev. 59, 863-918.

Vonkeman \& Van Dorp, D.A. (1968) The action of prostaglandin synthetase on 2-arachidonyl-lecithin. Biochim. Biophys. Acta 164, 430-432.

Wlodawer, P., Kindahl, H. \& Hamberg, M. (1976) Biosynthesis of prostaglandins from arachidonic acid and prostaglandin endoperoxides in the uterus. Biochim. Biophys. Acta 431, 603-614. 